\title{
Blockchain Innovation and Its Capacity to Enhance the Quality From Accounting Information Systems
}

\author{
Iman Supriadi ${ }^{1}$, Wulandari Harjanti ${ }^{2}$, Miya Dewi Suprihandari ${ }^{3}$, Hendra Dwi Prasetyo ${ }^{4}$,Muslikhun ${ }^{5}$ \\ Accounting major \\ Faculty of Economics, STIE Mahardhika Surabaya
}

\begin{abstract}
Blockchain is a promising technology for real-time accounting records and continuous monitoring. Blockchain innovation offers a technique for sharing data sources among individuals, also if they don't count on each other, and this produces a market for moving possessions based on peer-to-peer networks without a main authority. Blockchain innovation has drawn considerable financial investment from endeavor capitalists, multinational bankers, and the attention of regulators. This paper attempts to talk about the background from blockchain innovation, present use, and capacity applications that may enhance the timeliness, high quality, and precision from bookkeeping info. This paper will likewise assess the efficiency from some useful bookkeeping applications.
\end{abstract}

Keywords: Blockchain, Accounting Information System.

\section{Introduction}

Modern Information Technology changes the prerequisites for managerial and accounting procedures, modifying various ways such as sharing, aggregation and distribution of information, which leads to the emergence of a new accounting infrastructure. Changes that occur in the information technology sector can significantly modify the accounting system. The application of innovative advances in IT in accounting provides the opportunity to process large information in the shortest possible time. The use of cognitive technology not only accelerates data processing and analysis, but also ensures the implementation of global trends in transparency of control, accounting and reporting. Technology requirements such as transparency, quality and high level of information protection are in accordance with blockchain technology. This innovation distributes journals with a linked computer system network system instead of a central system. Blockchain is a computational information framework which contains all deals because the starting from the blockchain. This framework is duplicated and common amongst all taking part computer systems linked to the network. When a brand-new deal is sent, the deal is grouped along with various other deals as " obstructs " and regularly contributed to the front from the obstruct chain as the most recent deal " obstructs ". After the " obstruct " is acknowledged by many devices, taking part computer system networks upgrade their blockchain to show the blockchain got (Pilkington, 2015).

The rise of records kept up on the blockchain is exceptionally compelling to bookkeepers. The foundation of bookkeeping and revealing depends on twofold section accounting which is overseen in a few record structures. Extra records and sub-records are disseminated in the aggregation and support of monetary records. The organization of these large books consists of what constitutes generally accepted accounting principles. This principle serves as the basis for the objectives, uses and limitations of financial reporting in accordance with the general objectives of the Financial Accounting Standards Board. The efficient application from blockchain innovation right into the bookkeeping community has the capacity to enhance the high quality from info poured right into the monetary coverage procedure. The function from this research study paper is to talk about the beginnings from blockchain innovation, the present use this innovation, and capacity applications in bookkeeping and coverage. 


\section{Literature Review}

Blockchain technology is a distributed data system, where each participant is in the process of storing complete information about all operations (transactions) that cannot be tampered with, damaged, altered or stolen (Coyne \& McMickle, 2017; Kamińska, 2018). All transactions are stored in one registry, forming a decentralized structure for making decisions together. Because procedures are completely controlled in time, the present specify from the system is identified entirely by this deal sign up (Dai \& Vasarhelyi, 2017 ; Kwilinski, 2018). As a result, in other words, BlockChain is an electronic book, copies can be stored on thousands of computers throughout the world.

As a public list based on distributed accounting books, BlockChain provides each participant with a copy of his or her own information, with all changes displayed in almost all copies almost simultaneously (Karajovic et al., 2017). Each transaction is written as a data block, and each new block has an encrypted copy that is included in the previous block. This technology creates original information booklets where it is almost impossible to delete entries to hide some activities (Kokina et al., 2017). Unwittingly changing data in one of the blocks, because the system constantly checks the data in the block, and if something happens, for example, as a result of any transaction, it reports it, simultaneously recording new information in the new block (Potekhina \& Riumkin, 2017; Kwilinski et al., 2019).

Blockchain is an innovation dependent on appropriated records. Records comprise of "hinders" of data that are cryptographically bound together. This permits numerous gatherings to see the substance in the square while those in the square stay secured. Basic qualities of the blockchain incorporate ongoing dispersion, confirmation of each square by accord (utilization of cryptography), and approval of each square. It is hard to change the authentic record on the grounds that each exchange and expansion is coordinated. Blockchain additionally incorporates the program's capacity to do certain exchanges moving along without any more activity by the client (US House). Blockchain is additionally portrayed as "an advanced record of completely open financial exchanges, consistently refreshed by endless clients, and considered difficult to break. This is a rundown of continuous records on the square" (Carzolo 2017). To explain this definition, certain blockchain can redid to make it not completely accessible to the open yet just obvious to approved clients. "Blockchain has a few preferences. To start with, it at present exists as a shared system that doesn't have a solitary purpose of disappointment. On the off chance that there is a disappointment in any hub, the other hub will keep on working, keeping up framework accessibility and congruity. Second, practically all documentation is advanced and can be effectively applied to different applications. Third, all exchanges on the Blockchain are obvious to all members, with relating increment in review abilities and dependability. Fourth, modifications to the Blockchain are problematic and if such modifications occur, they will be seen by different clients and on the off chance that they are not approved, they won't be remembered for the square. The upsides of Blockchain innovation will wipe out outsiders, decrease exchange expenses, and cause change in numerous businesses "(Fanning and Focuses 2016).

The blockchain idea was created by an obscure individual utilizing a pen name (Nakamoto 2008). Nakamoto's making of Bitcoin was actualized in a distributed installment framework referenced by the blockchain innovation. What is novel about blockchain is that it makes inventive techniques for listing and records for information. Common account, an interesting component of the blockchain, permits the component of "trust" in different connections to be controlled by accord versus guarantee.

\section{Research Methods}

In the research process procedure, a set of general and specific scientific methods that are cognitive in nature are used. This type of research is qualitative where in studying the theoretical position and the current state of accounting operations, using academic generalization techniques, organizing, contrast evaluation and synthesis, monitoring and historic methods are executed. Improved definition of the organization and method of accounting operations using the methods of induction and deduction, grouping, theoretical generalizations. The drawing method is used to provide a visual representation of the results of the study.

Findings

\section{Current use of the Blockchain}

Cryptographic money like Bitcoin, Ethereum, and Litecoin have accumulated a lot of consideration and are referenced in blockchain innovation. Albeit new improvement is really taking shape, different substances are 
creating different employments of blockchain innovation to make business openings or take care of issues. The banking and monetary field is creating applications for universal installments, capital markets and exchange fund. Insurance agencies create shrewd agreements to use in settling claims. Business utilizes incorporate inventory network the board, wellbeing administration information record the executives, and land exchange history. Government utilizes incorporate record the executives, personality the board and casting a ballot.

Fundamentally, the blockchain permits new strategies to arrange, record and approve value-based records. Most records today require a brought together trust authority. Partnerships and government elements utilize different frameworks and access authority levels to keep up power over pertinent information and data. Utilizing a brought together biological system confines the measure of assets used to keep up information believability in this way improving the probability that human or framework debasement can happen without sufficient inward control. On the other hand, blockchain disposes of the requirement for concentrated authority by doling out trust components to an agreement based arrangement.

The case of production network the board may best show the progressive capability of blockchain innovation, Maersk. The biggest transportation organization on the planet finished its first trial of the blockchain innovation in Walk 2017, to perceive how it can assist take with minding of its freight. In testing, Maersk, Dutch traditions, and US Country Security would all be able to associate information about payload remotely, which appears if the innovation can encourage and ensure global delivery. Notwithstanding the proficiency of the data acquired, the utilization of this innovation can eventually ensure life on the grounds that right now rapidly recognizes the wellspring of foodborne sickness (Hacket 2017).

Despite the fact that the usage is still in its underlying stages, it isn't hard to conceptualize various applications. Blockchain can give lasting records that can't be altered about changes in the possession history of a benefit. Since information is viewed as the premise of rivalry, (Civi 2000), compelling execution of blockchain innovation will empower adopters to assemble upper hand in the market. An extra utilize that starts to change business collaborations is the advancement of "Savvy Agreements." Utilizing blockchain, decides are made that naturally execute contracts when certain criteria are met. For particular sorts of exchanges, this takes out mediators and repetitive records. This kind of Keen Agreement capacities like the "IF" work in Microsoft Exceed expectations; be that as it may, this capacity is shared between a few gatherings associated with the agreement. A model is a backup letter of credit. Rather than gathering the whole expected reports to be introduced to the outsider bank by the shipper/exporter, all means en route can be recorded, approved, stepped time, and set apart as complete to give constant reserve discharge after every single indicated condition are met.

There are numerous hindrances that point of confinement the prompt and unchallenged execution of blockchain innovation. Notwithstanding designating critical assets for mechanical availability, Deloitte has made a proof of idea blockchain group and built up a blockchain preparation system. Inside this structure they propose twenty inquiries that must be posed and addressed which will be key in driving the achievement or disappointment of the evidence of blockchain from idea ventures (Deloitte 2017). Blockchain execution will require generous exertion in arranging and actualizing procedures and methods and will doubtlessly not be viewed as a standard innovation improvement process.

\section{Potential Applications in Accounting Applications}

The greatest open door for bookkeeping additionally conveys noteworthy hazard. Despite the fact that the proficiency and precision of approval can increment with the utilization of the blockchain, clients should likewise acknowledge the danger of broadcasting data that has possibly exclusive or competitive innovations. Rather than putting away data with a focal power, for example, controlling an organization's database and/or general record, blockchain permits exchanges to be communicated on the disseminated records. This method takes care of two significant issues in the bookkeeping environment: one, it builds the exactness of data by asking numerous gatherings to approve and inquiry input. Second, whenever utilized related to a review, it gives review proof that can be utilized as a major aspect of an underwriting. Inspectors who work with customers will have the option to incorporate substantive testing by approaching the significant customer blockchain that structures the premise of fiscal summaries. Approval by means of blockchain is a substantive methodology with outside affirmation, a more significant level of proof than the information gave by the customer. The AICPA Seat as of late noticed that the utilization of the blockchain 
will permit evaluators to check a lot of routine information consequently permitting them to concentrate time on increasingly complex exchanges and controls (Tysiac 2017).

One approach to show the utilization of a blockchain that is reenacted in Figure 1 is to break down its utilization for recording and keeping up Records Receivable for one organization and the Records Payable record for another organization. Expect organization A regularly sends the item to the organization's fundamental client B and re-appropriates some portion of the procedure to an outsider satisfaction place.

An individual blockchain can be set up so the A\&B organization keeps up a joint record to verify and record Records Receivable for Organization An and Records Receivable for Organization B. The approved gatherings of each organization and outsider satisfaction community will approve the presence, valuation, and fulfillment of every exchange through concurred dependent on criteria. Subsequent to approving deals and buys underneath the General Acknowledged Bookkeeping Standards criteria, the "Keen Agreement" highlight will begin recording diary passages to mirror the effect of the exchange fiscal reports. This audit procedure by accord makes a public accountant structure that gives more noteworthy straightforwardness and exactness to every exchange. On the off chance that the organization experiences a budget report review, the blockchain can be gotten to by outer inspectors and structures the reason for substantive testing for certain money related records, for example, culmination and precision.

\section{Risks and Opportunities}

The potential open doors for utilizing blockchain are clear. Goldman Sachs takes note of that "Blockchain can possibly change the manner in which we purchase and sell, associate with the administration, and check the credibility of everything from property rights to natural vegetables. It joins web receptiveness with cryptographic security to give everybody a quicker and more secure approach to confirm features and assemble trust "(Goldman 2018). An enormous number of organizations have blockchain ventures in progress; In any case, it appears that full scale execution has not yet occurred. This may change when early adopters uncover examples of overcoming adversity.

One part of usage that isn't indicated is whether the advantages will exceed the expenses of execution. Full scale substitution of inheritance frameworks and procedures is as of now unreasonable on the grounds that the full advantages of blockchain innovation can't be acknowledged except if there is significant outside support. This displays a problem for implementers who need to move past the investigation arrange, can a critical capital use be advocated for an innovation that as of now has constrained use? The doubtlessly dispatches are ventures with explicit and tight degree that permit clear and auspicious development and examination. During the most recent innovation roundtable supported by the Bookkeeping Diary, a member anticipated the plausibility of an execution that states "I explicitly think the usage of the individual blockchain will show up first, in and around certain utilization situations where the progression of reasoning is high worth. At that point, after we pass the idea verification organize, we will see some innovators, organizations that we don't know today, accompany a few executioner applications, some executioner draws near, something inventive and transformative "(Drew 2017). This reasonable situation implies that the execution of blockchain innovation will be driven by enterprising arrangements versus the corporate order. There is a contrarian perspective that difficulties the potential significance of blockchain innovation. During this most recent Journalt Accountingancy roundtable of the most recent innovation, J.Carlton Collins likens the potential effect of blockchain innovation on the bookkeeping calling with the execution of XML innovation built up a couple of decades back. He noted "There were numerous guarantees in the innovation and numerous individuals accepted at the time that XML would change bookkeeping, and that just applies to SEC detailing organizations. They contend that this innovation is underutilized "(Drew 2017)

\section{Conclusion}

The rise of blockchain innovation can possibly upset the old methods for recording, sorting out, confirming and conveying data. Bookkeeping applications utilizing blockchain innovation are being grown however full scale appropriation and usage has not yet occurred. Blockchain innovation will positively be a thought for organizations that need to create by expanding the practicality, quality, and precision of bookkeeping data. Hypothetically the application's change to verification of achievement from an effective idea, the utilization of blockchain innovation will turn into a necessary piece of the data innovation biological system. 
Private Blockchain

Basic AR/AP Validation

(1) Enters Shipment Data
(2) Validates Quantity, Quality and, Receipt

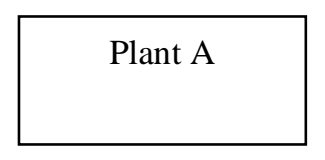

(4) Record AR when (1) \& (2) remain in contract by agreement in the blockchain

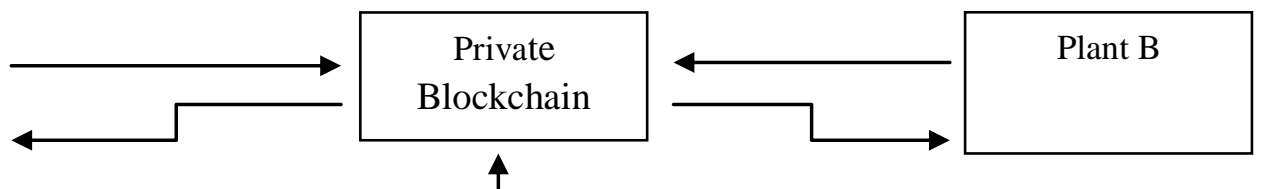

(3) Document AP when (1) \&

(2) remain in contract by agreement in the blockchain

(5) Adds info concerning phases from handling and conclusion to the personal blockchain

Source: J. Marshall McComb II (2018)

Figure 1. Illustration of Blockchain

\section{References}

[1] Aleksy Kwilinski. (2018). Implementation Of Blockchain Technology In Accounting Sphere. London Academy of Science and Business. Academy of Accounting and Financial Studies Journal. Volume 23, Special Issue 2

[2] Carlozo, L. (July 1, 2017). What is blockchain? Journal of Accoutancy.

[3] Civi, E. (2000). Knowledge Management as a Competetive Asset. Marketing Intelligence and Planning, 18(4), 166-174.

[4] Commerce, U.S House of Representatives Comitee on Energy and. (2016). The Disruper Series: Digital Currency and Blockchain Technology. Retrieved from

[5] Coyne, J.G., \& McMickle, P.L. (2017). Can blockchains serve an accounting purpose? Journal of Emerging Technologies in Accounting, 14(2), 101-111.

[6] Cremins, S., Andrzejweski, D., Singhal, M., \& Piscini, E. (2017). Taking Blockchain Live: The 20 questions that must be answered to move beyond proofs of concept. Deloitte Development.

[7] Dai,J., \& Vasarheli, M. A. (2017). Toward Blockchain-Based Acconting and Assurance. Journal of Information Systems, 5-21.

[8] Drew, J. (2017, 07 01). Real talk about artificial intelligence and blockchain. Journal of Accountancy.

[9] Fanning, J. (2017, 01 July). Real talk about artificial inttelligence and blockchain. Journal of Accountancy.

[10] Fanning, K., \& Centers, D. (2016). Blockchain and Its Coming Impact on Financial Services. Journal of Corporate Accounting and Finance, 27, 53-57.

[11] Hacket, R. (2017, September 01). Blockchain Mania. Fortune.

[12] J. Marshall McComb., \& Steven W. Smalt (2018). The rise of blockchain technology and its potential for improving the quality of accounting information. Kennesaw State University. Journal of Finance and Accountancy. Volume 23

[13] Johnstone, K., Grambling, A., \& Rittenberg, L. (n.d.). Auditing: A Risk Based Approach to Conducting a Quality Audit. 10e

[14] Karajovic, M., Kim, H.M., \& Laskowski, M. (2017). Thinking outside the block: Projected phases of blockchain integration in the accounting industry. Australian Accounting Review. from https://doi.org/10.1111/auar.12280

[15] Kokina, J., Mancha, R., \& Pachamanova, D. (2017). Blockchain: Emergent industry adoption and implications for accounting. Journal of Emerging Technologies in Accounting, 14(2), 91-100. 
[16] Nakamoto, S. (n.d.). Bitcoin: A Peer-to-Peer Electronic Cash System. Retrieved from https://bitcoin.org/bitcoin.pdf

[17] Pilkington, M. (n.d.). Research Handbookd on Digital Transformations. 225-253. doi: $10.4337 / 9781784717766.00019$

[18] Potekhina, A., \& Riumkin, I. (2017). Blockchain a new accounting paradigm: Implications for credit risk management. Retrieved from http://www.diva-portal.org/smash/get/diva2: 1114333/FULLTEXT01.pdf

[19] Sachs, Goldman. (n.d.). Blockchain - The New Technology of Trust. Retrieved 01 09, 2018, from http://www.goldmansachs.com/our-thinking/pages/blockchain/ 